\title{
A CASE OF CENTRAL NEUROFIBROMATOSIS
}

BY

\author{
L. CROME \\ From the Fountain Hospital, London
}

(RECEIVED FOR PUBLICATION JULY 6, 1962)

The clinical and pathological features of multiple neurofibromatosis (von Recklinghausen's disease) are usually striking and often rather bizarre. It has hence attracted much interest and is well described and illustrated. Recent accounts include those by Willis (1958) and Russell and Rubinstein (1959); a fuller review in German by Schmincke (1956) is mainly devoted to the description and interpretation of the nerve lesions. Of the many earlier reports, that of Preiser and Davenport (1918) retains, perhaps, most of its interest.

The disease is characterized by the occurrence of multiple dysplasic and proliferative changes in nerves, the central nervous system and other tissues. The skin is commonly affected, showing patchy brown pigmentation-café-au-lait spots, pigmented naevi, hamartomata, hypertrichosis and haemangiomata. The cutaneous neurofibromata may be sessile or pedunculated. Many other associated abnormalities have been observed, some frequently and others only occasionally, and perhaps, coincidentally. Thus, combination with the Ehlers-Danlos syndrome has been reported by Ormea and Depaoli (1954) and with dermatolysis (Alibert) by Schirren and Buhl (1959). Adenoma sebaceum, which is characteristic of tuberous sclerosis, may occur also in cases of multiple neurofibromatosis (Bodechtel, 1950), and renal hamartomata, as in tuberous sclerosis, were present in a case described by Schairer (1934). Skeletal anomalies have included spinal scoliosis and kyphoscoliosis (Allibone, Illingworth and Wright, 1960), atlanto-occipital fusion with basilar impression (Zacks, 1960), pseudoarthrosis of the tibia, general or localized acromegaly, dwarfism, asymmetry of the face and skull, pelvic deformity, anomalies of fingers and toes, and bony exostoses, cysts and pressure erosions. The cranial abnormalities have recently been discussed by Meinardus (1958). Changes reported in other organs included macroglossia, chromaffin tumours of the adrenals (Guenther, 1959), Turner's syndrome, ovarian dysplasia and pseudohermaphrodism. The intestinal manifestations of neurofibromatosis have been dealt with in detail by Feyrter (1948). In a number of publications Inglis (1950, 1952a, 1952b) expressed his hypothetical views on the interrelations between the manifold changes in this condition.

The commonest intracranial and intraspinal manifestations of the disease are involvement of the nerve roots and nerves, the lesions resembling, in the main, those of the peripheral nerves. Of the cranial nerves, the VIII and V seem to be most frequently affected, often bilaterally. The optic nerves may also be involved, but since their normal histological structure resembles the C.N.S. rather than other nerves, the change assumes the form of gliosis or gliomatosis. The meninges may show areas of multiple dysplasia or tumours, and a case of meningeal sarcomatosis was reported by Sillevis Smitt and Bijl (1955). Gliotic or gliomatous change may also occur, focally or diffusely, within the substance of the brain and spinal cord. More generalized encephalomyelopathy has been present in a few instances, e.g. hydrocephalus, meningomyelocele, syringomyelia and hydromyelia. The relative frequency of intrathoracic meningocele in cases of neurofibromatosis has been noted by Kessel (1951).

A notable feature of the condition is the wide histological range of the lesions which may present all gradations from scarcely recognizable dysplasia to hypertrophy, hyperplasia and benign or malignant neoplasm (Hosoi, 1931). It is generally accepted that the chief constituents of the lesion are the supporting elements of neural tissue: Schwann cells, fibrous tissue, blood vessels, meningeal structures and glial cells. Possible participation by neurons and their processes has been reported by some authors, but this is not generally accepted. Remnants of axis cylinders, myelin sheaths and neurons are, of course, commonly present among the proliferating elements within the lesions, and there is also some evidence of the usual local temporary neural regenerative processes. Thus, proliferative changes in the subcutaneous reticulum of the autonomic nervous system in the 'younger' skin lesions have been described by Thies (1954). Degenerative changes, including hyalinization, calcification, 
mucoid degeneration, partial or complete necrosis and calcification, are also quite common. Metaplasia to cartilage (chondrification) in a nerve sheath sarcoma in a case of neurofibromatosis has been reported by Payne (1960).

The heterogeneity of the lesions has stimulated a prolonged and often polemical discussion on the precise origin and nature of the proliferating tissue elements. This is reflected in the diversity of the nomenclature used by different authors to describe the peripheral nerve lesions: neuroma, pseudoneuroma, neurofibroma, fibroma, neurinoma, lemmoblastoma, neurilemmoma, perineurial fibroblastoma, peripheral glioma, fibroblastoma, and so on. Similarly, many different terms have been applied to the meningeal and glial lesions. The discussion seemed important owing to the significance attached at the time to the precise germ-layer derivation of the participating elements. It now appears somewhat dated in the light of the newer, more dynamic, orientation based on the recently won knowledge of inheritable changes in the composition of nucleic acids, and the influence that these exert on cellular metabolism at different stages of development and disease. It is known that neurofibromatosis may be inherited as a mendelian dominant (Preiser and Davenport, 1918) or originate as a new mutation, and the structure of the nucleic acids is presumably similarly abnormal in both cases. It may hence be inferred that as a result of this change the requirements of certain areas of neural tissue are not met, and that abnormal metabolites may under certain circumstances result from the anomalous genetic material, allowing an improperly controlled cellular proliferation of diverse tissue elements.

There may be two types of neurofibromatosis in accordance with the mode of distribution of the lesions (Russell and Rubinstein, 1959): one in which the peripheral manifestations are numerous and few or no central lesions are found, with the exception of the spinal roots which are often involved, and the second, in which there are few or no peripheral lesions. One might hence speak of the 'central' and the 'peripheral' types of multiple neurofibromatosis, although there is as yet no evidence of any fundamental difference between the two. Ortiz de Zarate (1954) has suggested that the term 'central' be reserved for cases showing involvement of the cerebrospinal axis and/or the optic and acoustic nerves.

It may be expected that central neurofibromatosis, which is frequently of early onset, would be often associated with mental retardation. Preiser and Davenport have in fact estimated the incidence of 'feeble-mindedness' in 243 published cases of neurofibromatosis at $7 \cdot 8 \%$. However, only two instances of the condition were found among 800 consecutive admissions of severely subnormal children at the Fountain Hospital between 1949 and 1960, one of which has been reported already (Crome, 1954). Likewise, Malamud (1952) found only one case of neurofibromatosis in his series of 512 cases. The condition may be somewhat more common among higher-grade patients. Thus, six cases were present among 1,280 mental defectives of all grades and ages surveyed by Penrose (1938), but in some of these the neurofibromatosis may have been incidental and unrelated causally to the mental retardation.

Central neurofibromatosis has received less attention in the literature than the peripheral disease, although some cases have been very well described (Bruce and Dawson, 1913; Kernohan and Parker, 1932; Bielschowsky and Rose, 1927; Katzenstein, 1932; Schairer, 1934; Shapland and Greenfield, 1935; Worster-Drought, Dickson and McMenemey, 1937; Turner and Gardner, 1938; Ortiz de Zarate, 1954; Poursines, Alliez and Tatossian, 1955; Rodriguez, Médoc and Beretervide, 1957; Jéquier and Rabinowicz, 1958). The following is another example of the condition, the second of the two cases at the Fountain Hospital referred to above. It presents some unusual clinical and pathological features.

\section{Case Report}

T.K. (P.M.70/61) was born to a father aged 36 and a mother aged 26 years. The mother attended an antenatal clinic throughout the pregnancy and was delivered in hospital. Nothing untoward was noted during pregnancy or labour. The child weighed $2.9 \mathrm{~kg}$. at birth and oppeared to be normal apart from the presence, according to the mother, of café-au-lait spots.

The father, a radio engineer, and the mother, a dressmaker, are Jewish and are both mentally and physically normal. There is no parental consanguinity. The parents have had four sons, one born before and two after the patient. The youngest attends a school for the educationally subnormal, but, when examined, showed no evidence of neurofibromatosis; the other two are normal. There is a history of cataracts in the maternal grandmother, two maternal uncles and a maternal aunt; the maternal grandmother is also reported to have had café-au-lait spots. There is no history of abnormality in other grandparents, uncles, aunts or first cousins.

The patient's early development was retarded. $\mathrm{He}$ sat up at 14 months and did not walk until the $22 \mathrm{n} 1$ month. When 2 years old, he was investigated in hospital and found to have café-au-lait spots, a neurofibroma in the right supraclavicular fossa (confirmed by biopsy), partial deafness and mental retardation. He was admitted to the Fountain Hospital, aet 4. 


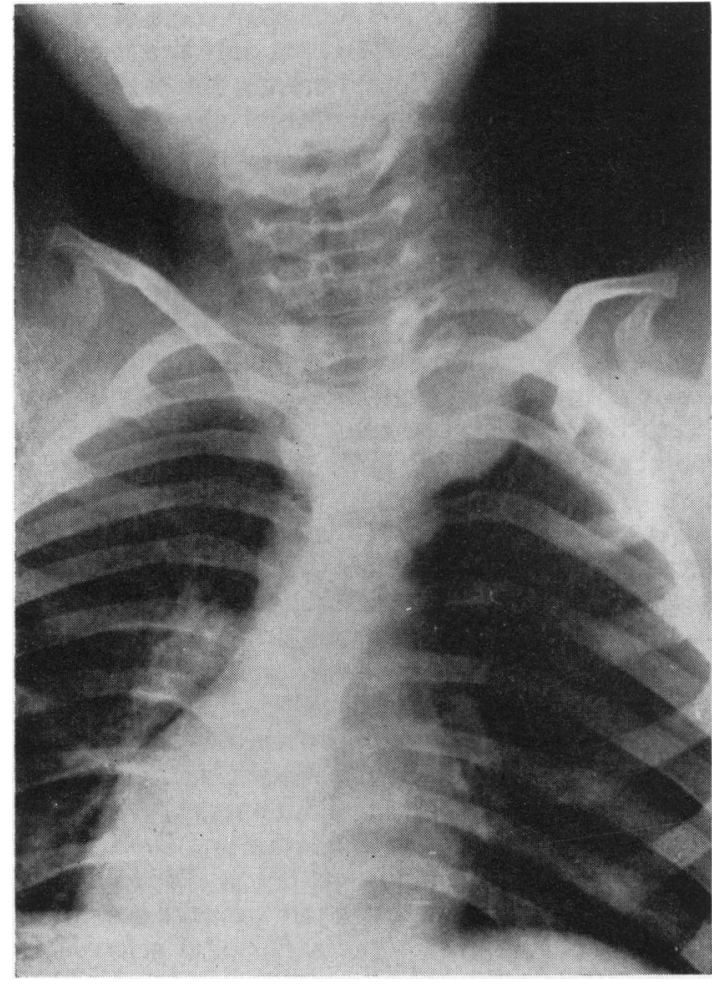

FIG. 1.-A radiograph taken at 4 sears shows a neurofibroma of the right vagus.

On admission he weighed $17.7 \mathrm{~kg}$., his height was $99 \mathrm{~cm}$., and head circumference $53.0 \mathrm{~cm}$. Café-au-lait spots were present on the trunk and limbs, and multiple naevi on the trunk alone. The child was partially deaf, and severely subnormal. His D.Q. on the Vineland Social Maturity Scale was 26. A radiograph of the chest showed a round right apical opacity consistent with a neurofibroma (Fig. 1). Several skull radiographs in the ensuing years, and radiographs of the hands and feet taken at 12 years, revealed no abnormalities. The D.Q. on the Vineland Social Maturity Scale was 18 at $8 \frac{1}{2}$ years and 15 at $10 \frac{3}{4}$ years.

When he was 11 years old marked hypochromic anaemia was noted with a somewhat fluctuating low level of haemoglobin, falling to $7 \cdot 9 \mathrm{~g} . / 100 \mathrm{ml}$. (Haldane), and punctate basophilia of the erythrocytes. Since he was prone to pica, the possibility of lead poisoning was considered, but examination of urine and serum for lead and porphyrins, and bone radiographs proved inconclusive.

He had a succession of grand-mal attacks at 11 years 10 months, and these recurred thereafter, in spite of medication, at intervals of a few months.

At 12 years he was noticed to be sleepy and had polydipsia and anorexia. Because of incontinence, his urine output was not measured. Dr. J. Burkinshaw, the consultant paediatrician, thought that these symptoms were compatible with a hypothalamic lesion and suggested a trial period of pitressin, but this suggestion was not taken up because a radiograph taken at the time showed no evidence of tumour in the hypothalamic region.

At 14 years the patient sustained an oblique fracture of the humerus. This was treated by an application of plaster of Paris, which the patient partially destroyed by chewing. The plaster was reapplied, but the patient died the following day with signs of intestinal obstruction and peritonitis.

\section{Pathological Findings}

Nervous System. The brain, dissected after prolonged fixation in formalin, weighed $1,570 \mathrm{~g}$. The meninges were smooth and transparent. The pattern of gyri was normal and the main blood vessels showed no abnormality. Both olfactory bulbs were unduly prominent and firm; the olfactory tracts and all other cranial nerves were normal. It had been noted at autopsy that a tumefaction was present in the region of the tuber cinereum, which was more obvious on palpation than inspection. More careful examination on dissecting the affected area showed discoloration, slight enlargement and induration of the entire hypothalamus, including the floor of the third ventricle and the mamillary bodies. The involvement was bilateral, but more marked on the right side. It extended upwards and backwards to involve part of the anterior nucleus of the thalamus, the transition to normal structure being indistinct.

The cerebral cortex presented many small foci of pale discoloration. The hippocampus was shrunken and indurated. The basal ganglia, ventricles and ventricular lining seemed normal.

The white matter of both cerebral hemispheres was split by central vertical clefts extending along most of the hemisphere. It was uncertain whether these were anteor post-mortem in origin.

The cerebellum, which weighed, together with the brain-stem, 209 g., showed focal sclerosis of the folia, especially along its posterior margin, and gliotic obliteration of the pattern of the peripheral half of the dentate nucleus.

The brain-stem and spinal cord were normal. Many fusiform, cylindrical and nodular expansions were situated along the course of spinal nerve roots and nerves. Some of the nerve roots and cords of the cauda equina were not only thickened, but fused with each other (Fig. 2). The largest tumour, a plum-sized nodule, in part extra- and in part intrathecal, was found in the cervical region. It received, like some of the other nodules, the insertion of nerve roots from several spinal segments. Both vagi also contained several nodules along their cervical and upper thoracic course, the largest measuring $2.5 \times 2 \times 1 \mathrm{~cm}$. The brachial and sacral plexuses and many peripheral nerves were searched for neurofibromata at autopsy, but none was found. The structure of all neural nodules was somewhat similar. They were firm on palpation, enveloped by a stout fibrous capsule, and showed a glistening whitish cut surface with occasional indistinct fibrous markings. 


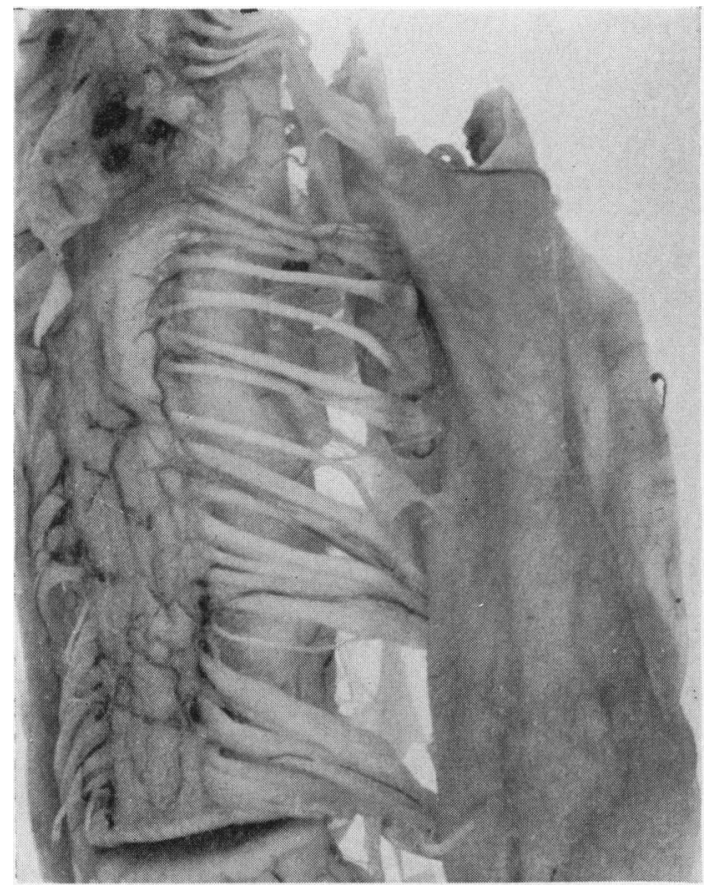

FIG. 2.-Cervical cord with dura reflected sideways. Fusion of some nerve roots and insertion of roots from several segments into a partly intra- and partly extrathecal neurofibroma.

Only a single subcutaneous tumour was found: a lobulated softish mass, about $5 \mathrm{~cm}$. in diameter, situated in the left suprascapular region.

Histological Features. Blocks taken from many levels of the central and peripheral nervous system were examined after celloidin and paraffin embedding and treatment by the usual pathological and neuropathological methods. Frozen sections were used for silver impregnation and fat staining.

The changes in the nervous system can be described as localized and diffuse.

Localized Changes. The cerebral cortex showed many areas, usually near the bottom of the sulci, that contained numerous pseudocalcium particles, i.e. deeply basophil, P.A.S. positive, roundish, homogeneous or laminated structures, most of which were negative in von Kossa preparations for calcium, with only a few showing early central calcification. The larger of these particles were scattered in a seemingly haphazard fashion through the affected areas, while the smaller ones tended to be arranged in rows along and within the walls of the smaller blood vessels. The neurons and glial cells in some of the areas containing pseudocalcium stained feebly by most of the usual methods bestowing upon the affected field a somewhat shadowy, ghostlike appearance. Less numerous areas of pseudocalcium deposition were also

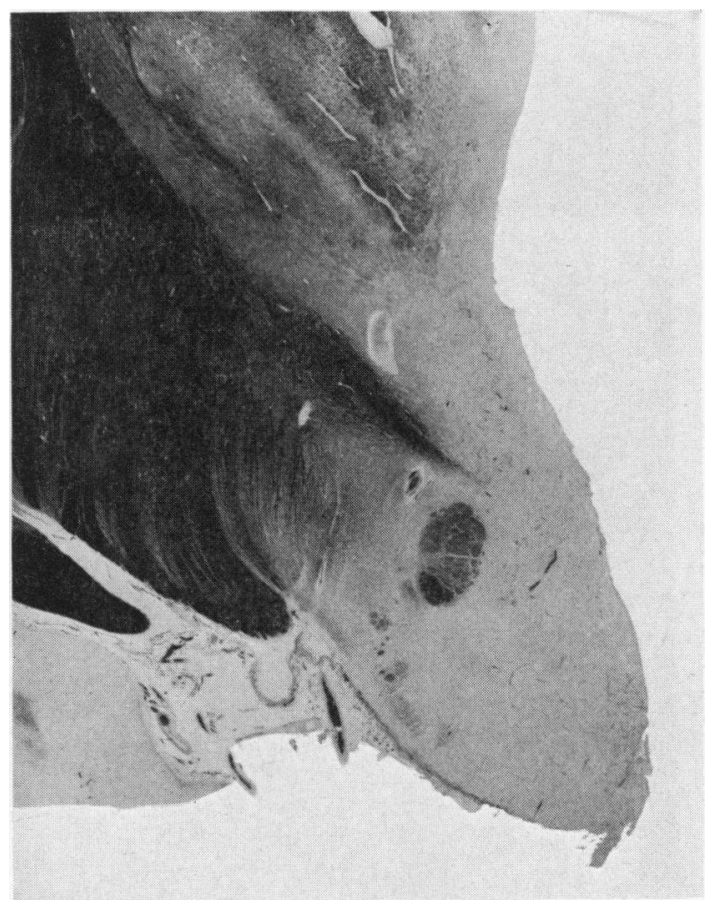

Fig. 3. - The hypothalamus is enlarged and the normally acute angle formed by its lowermost portion is blunted. The myelin of the fornix is pale. (Heidenhain $\times 3 \cdot 5$.)

present in the cerebral white matter, basal ganglia and cerebellar cortex and white matter.

Naked-eye inspection of stained coronal sections showed that the hypothalamus was unduly 'full' and that the acute angle normally formed by its lowermost portion was considerably blunted (Fig. 3). The area was densely gliotic, most of the cells being of the usual fibre-bearing astrocytic type. Larger cells had vesicular, oval, reniform or irregular, greatly convoluted nuclei. Many glial cells were arranged in pairs or larger clusters. Because of the complex nuclear folding, it was usually impossible to examine the whole structure in a single plane. A few of the larger cells showed also a faintly outlined cytoplasm containing minute indistinct granules, thus resembling the Alzheimer Type I cells, which are occasionally present in the neural lesions of hepatolenticular degeneration. Most of the glial fibres formed a complex dense network, but some were arranged in parallel undulating or whorled bundles (Fig. 4). Irregularly shaped hyaline bodies, Rosenthal fibres, were present between the glial fibres in the peripheral parts of the hypothalamus. Neurons were only seen in the more central parts of the gliotic area, and many were obviously deformed by the surrounding gliosis. The fornix and the mamillo-thalamic tracts showed pallor of myelin staining. Several large flattish sub-ependymal glial plaques were situated in the wall of the third ventricle.

The hippocampus was densely gliotic but not enlarged. 

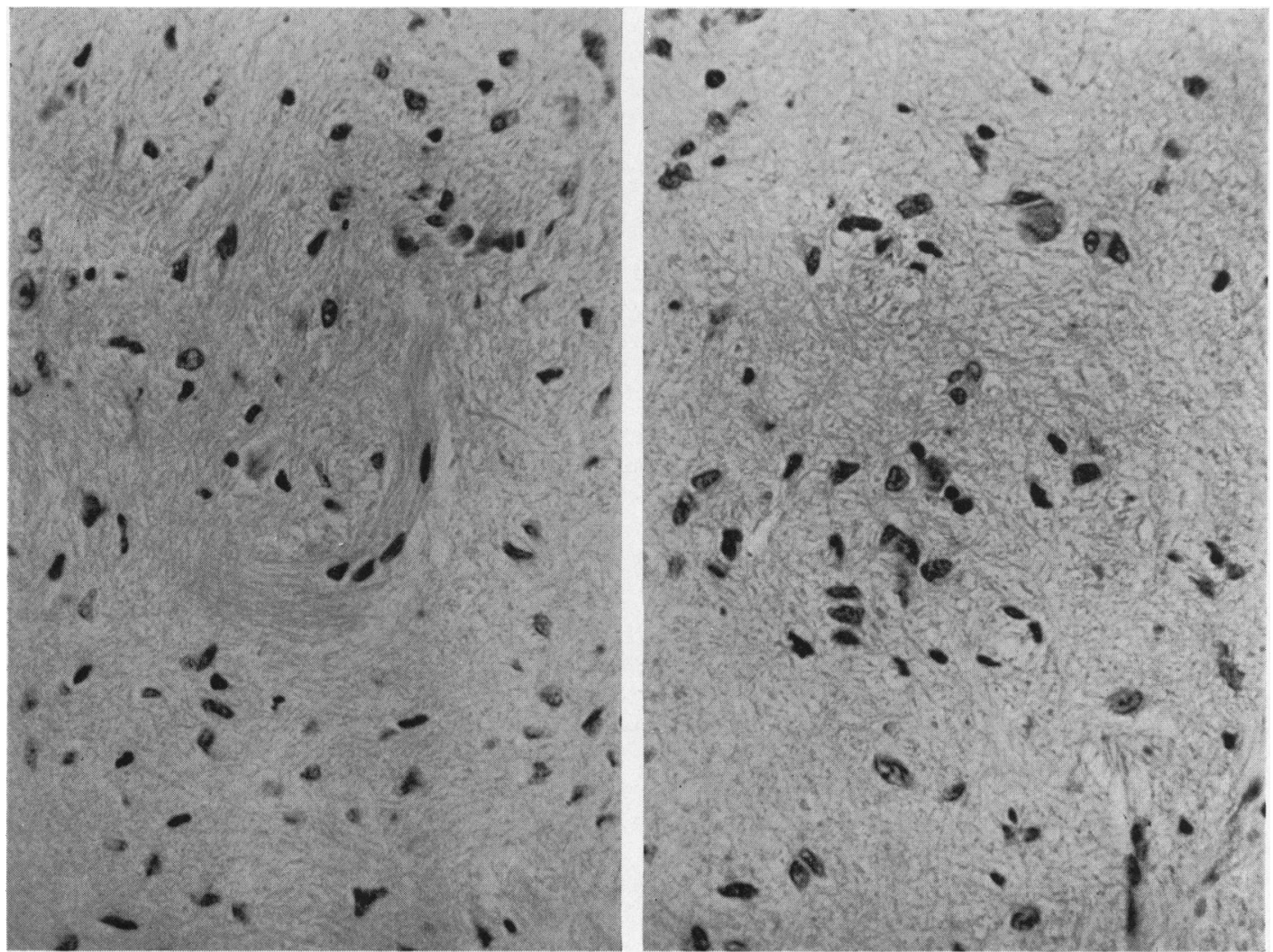

FIG. 4.-The pattern of gliosis in the hypothalamus. Bundles of glial fibres on left, and clusters of larger cells, right. (H. and E. $\times 400$.)

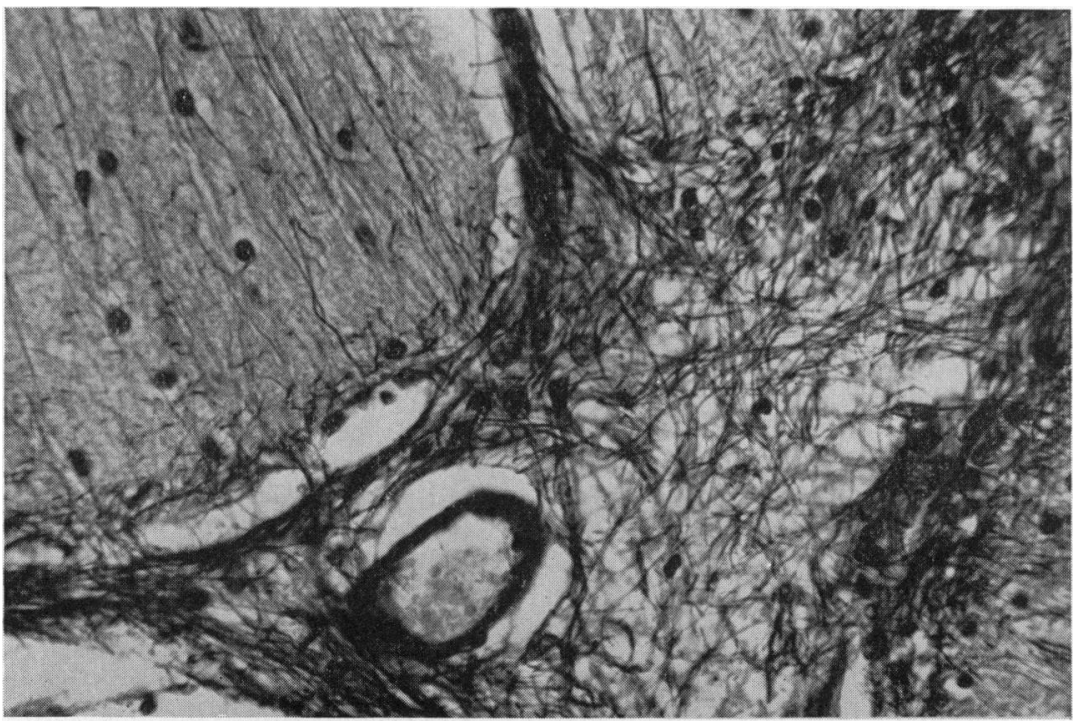

Fig. 5.-Glial fibres bridging interfolial cerebellar spaces. (Holzer $\times 400$.) 


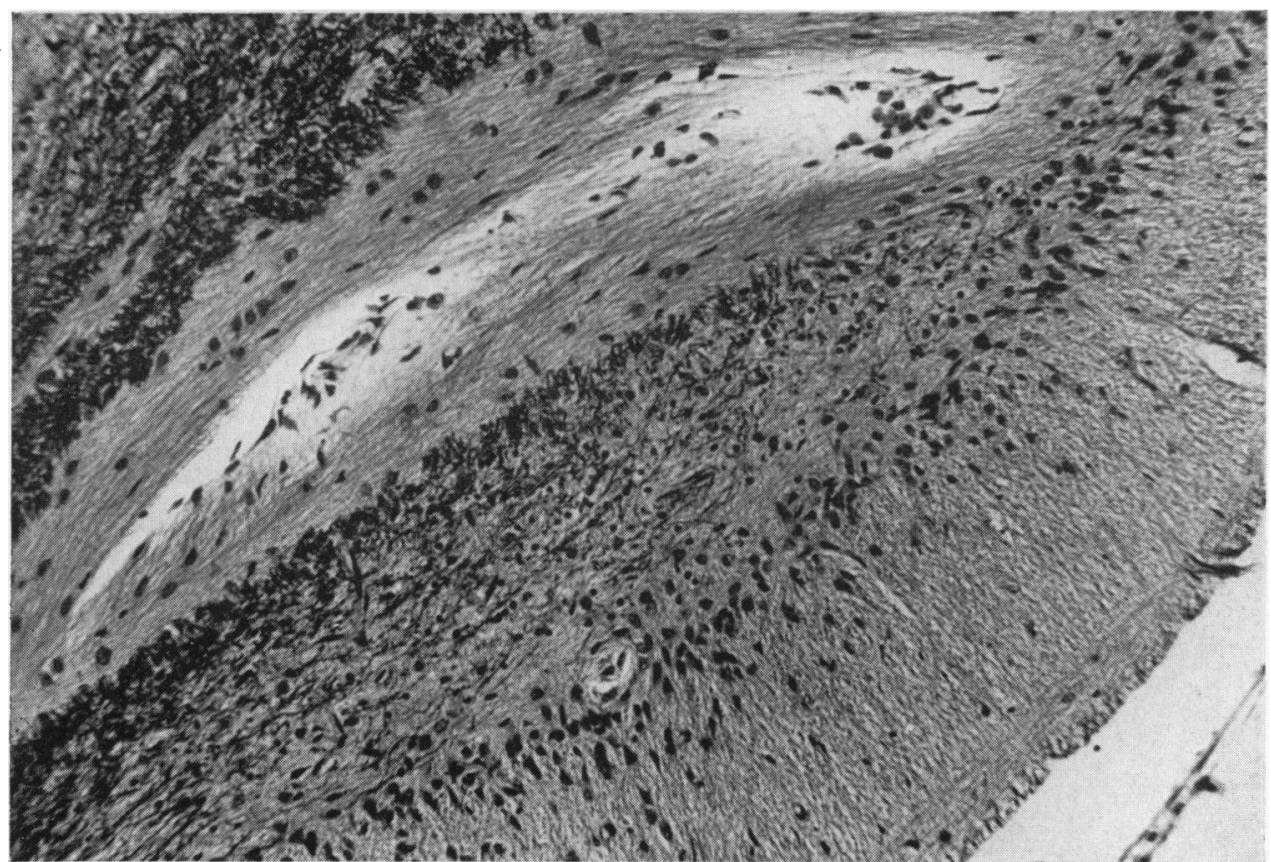

Fig. 6.-Sclerotic cerebellar folium showing only a few layers of Bergmann glia. A blood vessel in the white matter is cuffed by a sleeve of dense glial tissue. (Metrazol fast blue and cresyl violet $\times 166$.)

Almost all neurons had disappeared in this formation.

Some blood vessels in the cerebral white matter were occluded by intravascular fibrous casts. The large clefts seen on naked-eye inspection showed no reactive changes around their margins, and since many blood vessels were filled by large Gram-positive organisms,

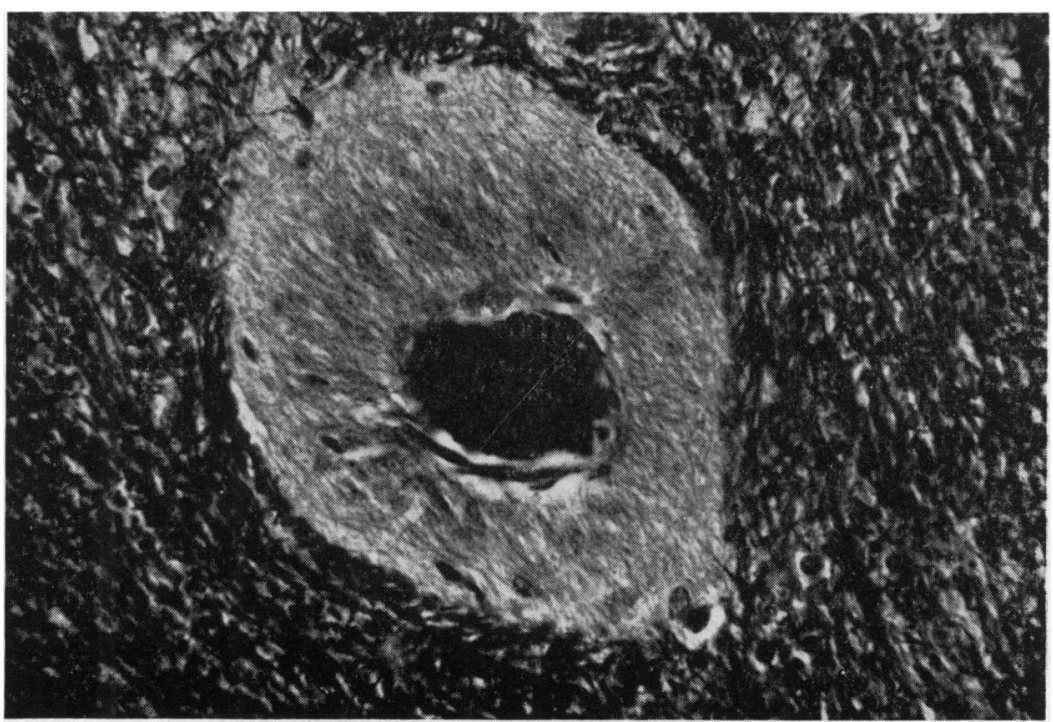

Fig. 7.-A blood vessel in the cerebellar white matter is cuffed by dense glial tissue. (Metrazol fast blue $\times 400$.) 


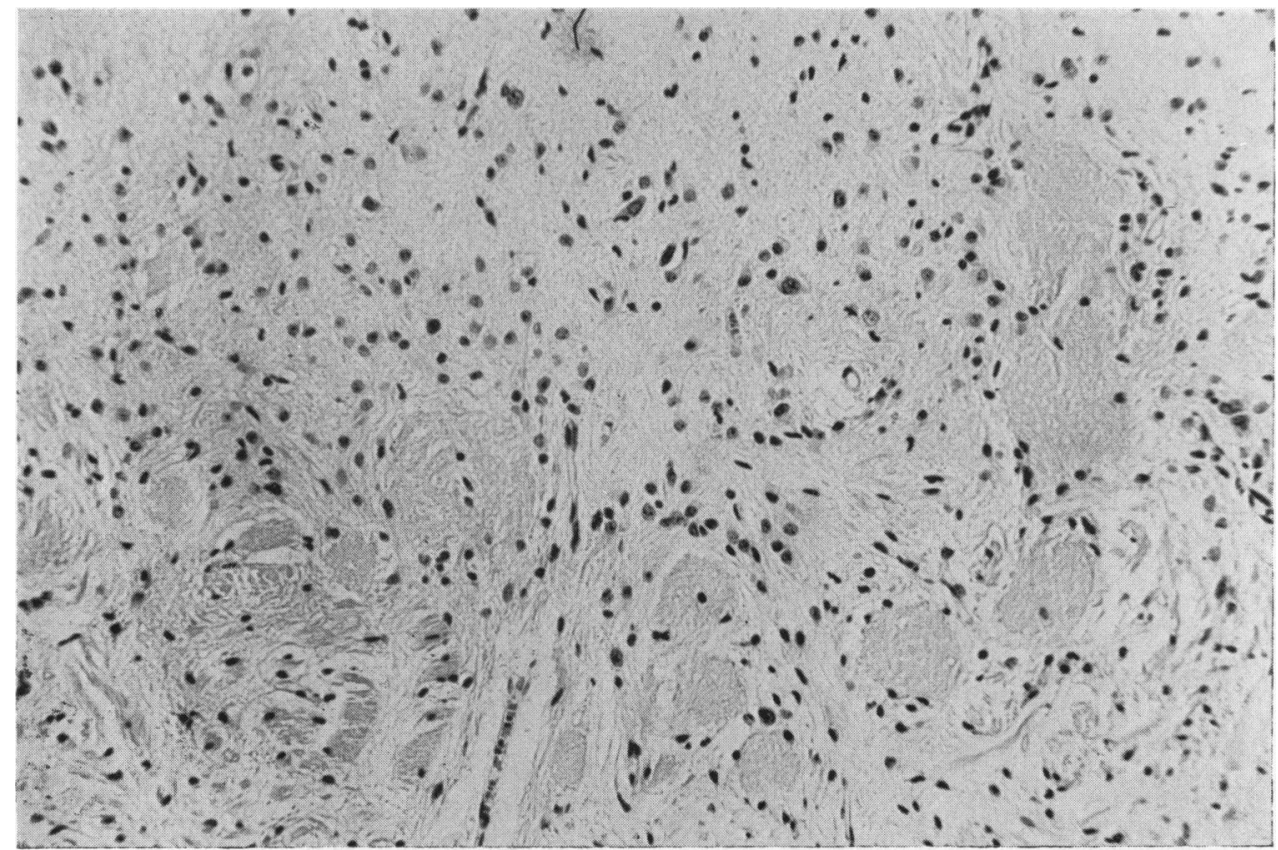

FIG. 8. -Gliosis of the olfactory bulb. (H. and E. $\times 240$.)

the cavitation was doubtless the result of post-mortem bacterial fermentation.

Cerebellar changes were very conspicuous and manifold. The Purkinje cells, granules and basket cells had entirely disappeared in many folia and were replaced by only a few layers of Bergmann glia. These folia showed very dense fibrous gliosis and total myelin loss. Some of the glial tissue extended beyond the outer margin of the molecular layer across the interfolial spaces, cementing in this way neighbouring folia (Fig. 5). This ectopic tissue had the usual staining properties of the glial cells and fibres, although some reticulin fibres were also present in the walls of the incident blood vessels. As in the case of other gliotic foci, the margins of the cerebellar lesions were ill defined, the adjoining areas showing lesser degrees of similar changes. Many Purkinje cells were displaced well into the molecular layer, there was some loss of both Purkinje cells and granules, and a varying degree of gliosis. On the other hand, there were also many structurally normal folia, showing only some conglutination of cells in the granular layer. The dentate nucleus was greatly depleted of cells and considerably involved by pseudocalcium deposition. Another widespread focal cerebellar change was the presence of 'sleeves' formed by very dense rather acellular glial tissue (Figs. 6 and 7) around many blood vessels.

A hypertrophic gliotic focus was present in the medulla at the level of the calamus scriptorius, its histological structure resembling that of the hypothalamic lesion. The inferior dorsal part of the fourth ventricle was 'roofed over' by this gliotic tissue and the ventricular cavity split into several narrow channels lined by ependymal cells. The area postrema was distorted and elongated. As in the hypothalamus, some Rosenthal fibres were present in this lesion.

The olfactory bulbs showed moderate neuronal and glomerular loss with hyperplasia of fibre-forming glial cells. The latter were distributed rather unevenly throughout the formation, tending to form localized cellular clusters (Fig. 8). A layer of spongy rarefaction with localized complete breakdown of tissue was seen in one sector between the glomeruli and the mitre cells.

The cortico-pontine and cortico-spinal tracts in the brain-stem and spinal cord showed pallor of myelin staining.

In spite of considerable variation in the degiee of histological change in the peripheral nerve lesions, all were fundamentally similar. The mildest presented only as widening of the spaces between neighbouring axis cylinders and Schwann cells, the latter being somewhat enlarged and hyperplastic. In the more hypertrophic areas the parenchymatous structures were often well preserved in the centre of the nerve or at its periphery, with hyperplasia, cellular enlargement and widening of the intercellular spaces present elsewhere. With the increasing cellularity of the lesions, pleomorphism and the density of the proliferating cells became more marked and there was a corresponding reduction in the number of remaining axis cylinders and myelin sheaths, only their occasional distorted and truncated fragments remaining in the affected areas. There was also an 
increase in collagen and reticulin fibres. Numerous histiocytic cells were present between the undulating rows of proliferating Schwann cells. The cytoplasm of these histiocytes showed every transition from a solid homogeneous state to fully foam-like structures. The most advanced lesions presented as densely cellular neurofibroma formed mainly by spindle-shaped cells with a few multinucleate elements, and containing no traceable remnants of parenchyma (Fig. 9). As in the case of the central lesions, the transition between the pathological and normal tissue was often ill defined, and it was frequently impossible to decide whether any particular area was abnormal.

In some of the dorsal root ganglia these changes affected one or both of the attached nerve roots, the surviving ganglion cells being sometimes deformed and widely separated from each other by the proliferating tissue. In other ganglia, only the nerve roots were affected, the formation itself remaining basically intact, although many neurons had disappeared and were represented by clusters of glial cells. An excess of lipochrome granules was present in the cytoplasm of many of the remaining neurons.

Diffuse Changes. All the larger nerve cells throughout the central nervous system showed terminal central chromatolysis and uneven staining. Similarly, many myelin sheaths were irregular in outline, beaded or fragmented. Neuronal lamination was well preserved in the cerebral cortex. There was no focal or laminar neuronal loss, but possible slight diffuse loss could not be excluded.

The white matter of the cerebral hemispheres showed generalized pallor of myelin staining with local preservation of better staining myelin 'islands' (Fig. 10). Blood vessels were occasionally, but by no means frequently, seen in the centres of these islands. Diffuse fibrous gliosis was present throughout the white matter, being often accentuated around blood vessels. The basal ganglia showed more marked fibrous and cellular gliosis, especially in the globus pallidus, the thalamus and the amygdaloid nucleus. The cellular composition of the glial tissue in areas of diffuse gliosis was, on the whole, as in the already described gliotic foci.

The brain-stem showed similar well-marked gliosis, especially of the substantia nigra, the midline structures, around the aqueduct and fourth ventricle, and of the inferior olives, which also showed focal loss of nerve cells. Similar gliosis was present throughout the grey matter of the spinal cord, where it extended in an irregular manner to the adjoining parts of the lateral and anterior columns (Fig. 11). Loss of nerve cells was uncertain in the spinal grey matter, but it was not always possible to distinguish neurons from the larger glial cells, many of which were distorted by the gliosis. Pallor of myelin staining was present in the anterior and lateral columns of the spinal cord.

Although the gliotic changes in the central nervous system were described as either diffuse or focal, the distinction between these was by no means clear cut. The cellular composition of the gliotic areas was, as already stated, similar, and smaller focal accentuations of the diffuse changes were widespread. It was also impossible to detect a definite histological difference between the hypertrophic and non-hypertrophic gliotic

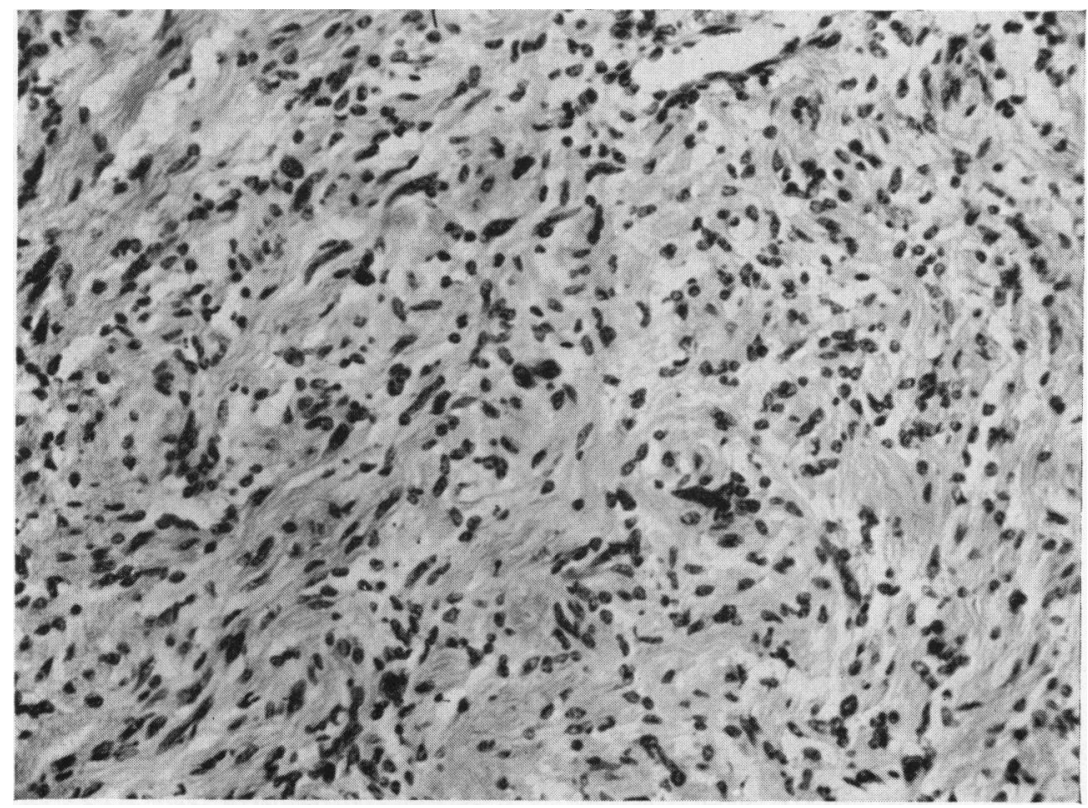

FIG. 9.-Peripheral neurofibroma. (H. and E. $\times 240$.) 


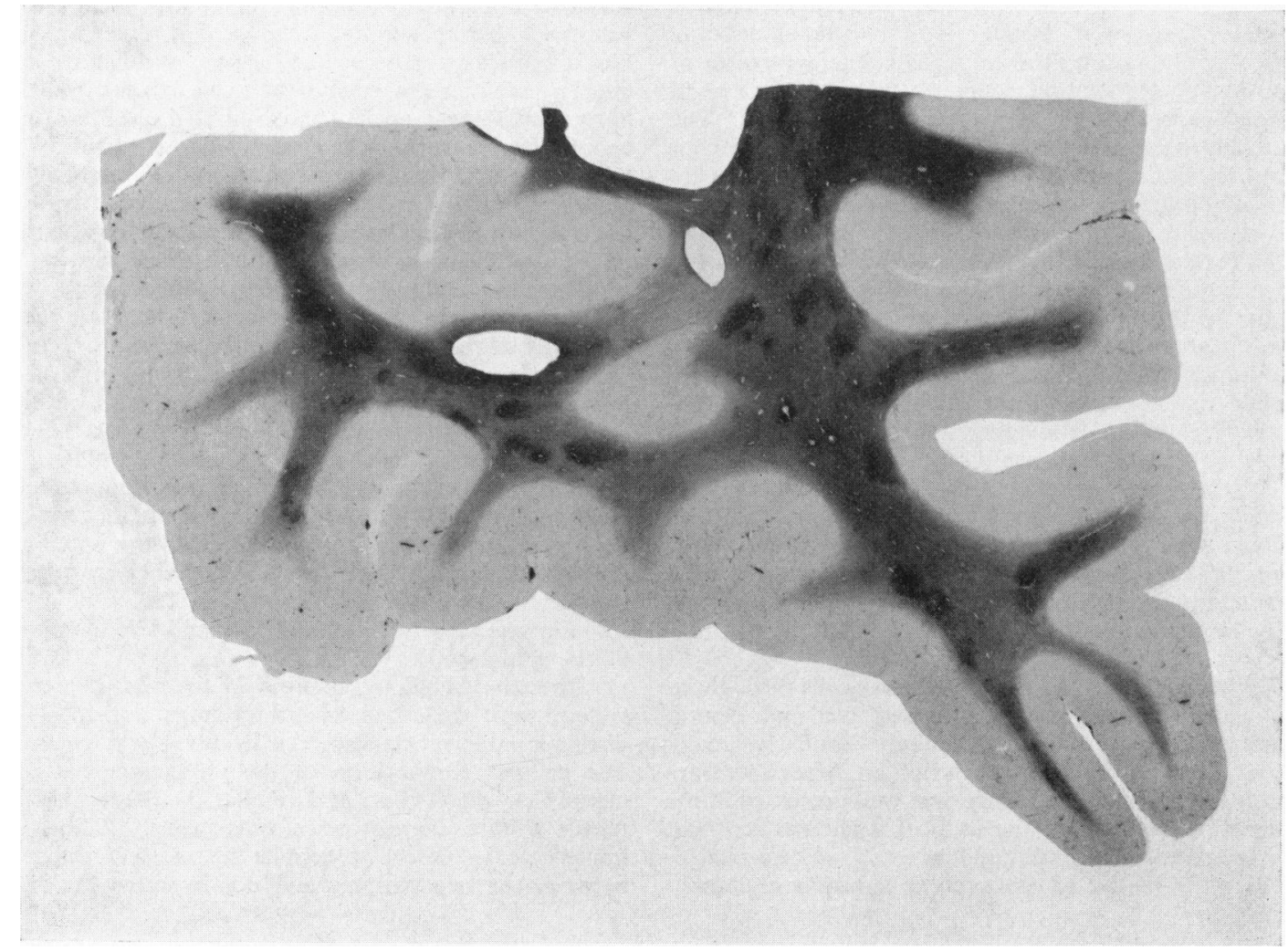

Fig. 10.-Frontal lobe with loss of white matter and preservation of myelin islands. (Heidenhain $\times 3$.)

foci. Some gliotic areas were shrunken, but most were normal in volume, while a few were hypertrophic. There was no histological difference between these lesions other than the density and number of constituent glial cells and their processes, and the occasional presence of Rosentha! fibres in the more hypertrophic areas. It may thus be correct to sum up these changes as generalized diffuse gliosis with local accentuations in density, and occasional hypertrophy.

Frozen sections stained for fat showed a moderate number of intracellular bright sudanophil particles situated mainly around the smaller blood vessels in the denser gliotic foci. The amount of sudanophil material elsewhere was minimal.

Somatic Tissues. Autopsy was performed 12 hours after death. The left arm was encased in a plaster of Paris cast; the left humerus was fractured. Marked kyphoscoliosis was present in the upper part of the spine. The skin of the entire body was covered by café-au-lait spots, most of which were minute. The secondary sexual characters were normal. The trachea and main bronchi were inflamed, containing some inhaled gastric material. The heart (150 g.) was normal. The abdomen was distended, there was early peritonitis, and most of the small intestine was necrotic. About 1.5 metres from the duodenojejunal junction the intestine was obstructed by an egg-sized 'ball' of crumpled celluloid with sharp edges, one of which had perforated the gut. The liver $(1,095$ g.), thyroid (7.8 g.) and adrenals (right, 6.57; left, 8.49) seemed normal. The spleen (110 g.) was soft, but its pulp was not diffluent. The kidneys weighed 92 and $93 \mathrm{~g}$. The renal cortex was pale and swollen. The testes weighed $25 \mathrm{~g}$. each.

Histological Findings. The tissues examined, after paraffin embedding, comprised the lungs, intestine, pituitary, liver, adrenals, testes, heart, spleen, kidney and eyes.

The small intestine showed haemorrhagic necrosis. The lungs were oedematous and showed some digestion by inhaled acid material. The pituitary was normal. Normal spermatogenesis was present in the testes. The kidney showed intimal proliferation of some cortical arteries with wedge-shaped areas of superficial ischaemic change in many stages of organization. The other tissues were normal. 


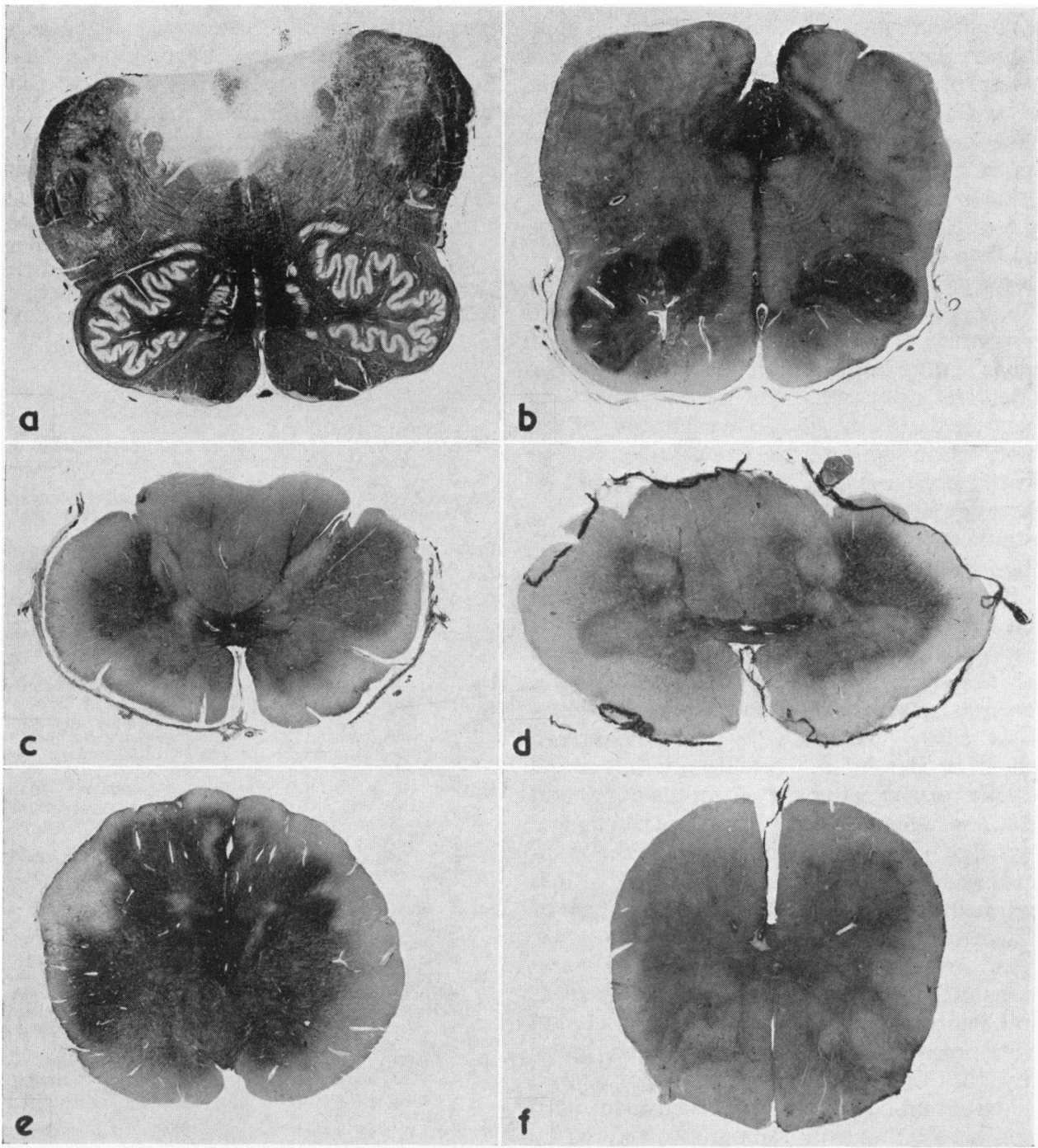

FIG. 11.-(a) Medulla showing pallor of myelin staining in the pyramids. (Heidenhain $\times 3 \cdot 5).(b)$ Medulla. Hypertrophic gliosis at calamus scriptorius and dense gliosis of midline structures and inferior olives. (Holzer $\times 3 \cdot 5).(c)$ and $(d)$ Cervical cord showing gliosis of grey matter extending irregularly to lateral and anterior columns. (Holzer $\times 5$.) $(e)$ Lower portion of medulla showing dense central gliosis. (Holzer $\times 3 \cdot 5$.) $(f)$ Sacral cord. (Holzer $\times 5$.)

\section{Discussion}

The pathological findings in the present case are characteristic for central neurofibromatosis, and some of the more unusual features have been noted in a few of the previously described cases. Thus, Case II of Lambers and Ortiz de Zarate (1952), a hydrocephalic girl who died at 3 years, had among other lesions, a subependymal 'spongioblastoma' in the tuber cinereum and at the posterior angle of the optic chiasma. The description of the histological changes indicated that the lesion was similar to that of the present case, although clinical signs referable to hypothalamic involvement were not reported. This case showed also tufts of glial tissue protruding from the molecular layer into the meningeal spaces at the base of the brain, and an area of hypertrophic 
gliosis at the level of the calamus scriptorius. Other cases (Scharenberg and Jones, 1956; Jéquier and Rabinowicz, 1958) displayed, like the present one, islets of glial tissue between the cerebellar folia. This phenomenon can evidently assume grosser form, as in the case described by Harbitz (1932) where similar gliotic tissue infiltrated the meninges, forming a thick sheet around the spinal cord, brainstem and base of the brain.

Extensive diffuse myelin loss in the cerebral white matter with sparing of 'islands' has not been previously reported in neurofibromatosis, although it is a familiar feature in the rare Pelizaeus-Merzbacher type of Schilder's disease.

As mentioned already, gliotic hypertrophy of the cranial nerves in neurofibromatosis is known to occur in the optic nerves. Similar involvement of the olfactory bulbs has apparently been reported only in three cases, and is believed not to occur on its own, without neurofibromatosis (Henschen, 1955). However, the olfactory bulbs are seldom examined without special need, and since the gliosis may be macroscopically inconspicuous, many abnormalities probably remain undetected.

The mental retardation in cases of neurofibromatosis is easily explicable by the widespread involvement of the brain. Intelligence is normal in most patients who suffer only from the peripheral manifestations of the disease. It is hence reasonable to assume that the possible alteration in the composition of genetic material, i.e. nucleic acids, does not impair neural function by itself, in the absence of cerebral structural change.

Diabetes insipidus has been mentioned as a possible manifestation of hypothalamic involvement in central neurofibromatosis by Bodechtel (1950), along with precocious puberty and adiposo-genital dystrophy, but this statement was not supported by a reference to actual cases. It is instructive to recall in this connexion, that skull radiographs showed no hypothalamic lesion in the present case, and this is understandable since the heavily gliotic area was not sufficiently enlarged to show in the radiograph.

\section{Summary}

A boy with no clear family history of neurofibromatosis was born with café-au-lait spots and one cutaneous neurofibroma. His mental development was grossly retarded and he began having grand-mal attacks at 12 years. Anorexia, sleepiness and polydipsia suggested diabetes insipidus caused by a hypothalamic lesion, but a skull radiograph was normal. He died at 14 years. Autopsy showed multiple neurofibromata of the vagi, spinal nerve roots and nerves. The brain and spinal cord presented areas of diffuse and focal gliosis, and some of these lesions were hypertrophic, viz. in the hypothalamus, olfactory bulbs and at the level of the calamus scriptorius of the medulla. The white matter of the cerebral hemispheres showed widespread loss of myelin with sparing of 'islands', as in the Pelizaeus-Merzbacher type of diffuse sclerosis.

I am grateful to Dr. S. Yudkin for his comments on the early period of the child's illness, and to my colleagues at the Fountain Hospital, especially Dr. Berg, for access to their records and for useful comments on this article.

\section{REFERENCES}

Allibone, E. C., Illingworth, R. S. and Wright, T. (1960). Neurofibromatosis (von Recklinghausen's disease) of the vertebral column. Arch. Dis. Childh., 35, 153.

Bielschowsky, M. and Rose, M. (1927). Zur Kenntnis der zentralen Veränderungen bei Recklinghausenschen Krankheit. J. Psychol. Neurol. (Lpz.), 35, 42.

Bodechtel, G. (1950). Zur Klinik der zentralen Formen der Neurofibromatose (Recklinghausen). Arch. Psychiat. Nervenkr., $185,326$.

Bruce, A. and Dawson, J. W. (1913). Multiple neuromata of the central nervous system: their structure and histogenesis. Rev. Neurol. Psychiat., 11, 117.

Crome, L. (1954). A case of central neurofibromatosis. J. Path. Bact., 67, 407

Feyrter, F. (1948). Über Neurome und Neurofibromatose, nach Untersuchungen am menschlichen Magendarmschlauch. Maudrich, Vienna.

Guenther, V. G. (1959). Pheochromocytoma associated with von Recklinghausen's disease. Wis. med. J., 58, 549.

Harbitz, F. (1932). Über das gleichzeitige Auftreten multipler Neurofibrome und Gliome (Gliomatose), auf erblicher Grundlage und mit diffuser Verbreitung in den Rückenmarks Gehirnhäuten. Acta path. microbiol. (Scand.), 9, 359

Henschen, F. (1955). Die Tumoren der Hirnnerven. In O. Lubarsch, F. Henke and R. Rössle's Handbuch der speziellen pathologischen Anatomie und Histologie, Band 13, Nervensystem, part 3, p. 805, ed. W. Scholz. Springer, Berlin.

Hosoi, K. (1931). Multiple neurofibromatosis (von Recklinghausen's disease) with special reference to malignant transformation. Arch. Surg. (Chicago), 22, 258.

Inglis, K. (1950). The nature of neurofibromatosis and related lesions, with special reference to certain lesions of bones: illustrating the influence of intrinsic factors in disease when development of the body is abnormal. J. Path. Bact., 62, 519 .

(1952a). The nature of agenesis and deficiency of parts. The influence of intrinsic factors in disease when development of the body is abnormal, as illustrated by agenesis of the digits, facial hemiatrophy, and cerebral agyria and microgyria. Amer. J. Path., 28, 449.

(1952b). The extraneural pathology of mental deficiency. In Proceedings of the First International Congress of Neuropathology, Rome, 1952, Vol. 2, p. 183. Rosenberg and Sellier, Torino.

Jéquier, M. and Rabinowicz, T. (1958). Lésions centrales dans la maladie de Recklinghausen. Rev. neurol., 98, 391.

Kernohan, J. W. and Parker, H. L. (1932). A case of Recklinghausen's disease with observations on the associated formation of tumors. J. nerv. ment. Dis., 76, 313.

Katzenstein, R. (1932). Úber innere Recklinghausensche Krankheit (Endotheliome, Neurinome, Gliome, Gliose, Hydromyelie). Virchows Arch. path. Anat., 286, 42.

Kessel, A. W. L. (1951). Intrathoracic meningocele, spinal deformity, and multiple neurofibromatosis. J. Bone Jt Surg., 33B, 87.

Lambers, K. and Ortiz de Zarate, J. C. (1952). Zentrale und periphere Neurofibromatose unter besonderer Berücksichtigung ihrer Beziehungen zur hypertrophischen Neuritis. Dtsch. $Z$. Nervenheilk., 169, 289.

Malamud, N. (1952). In Proceedings of the First International Congress of Neuropathology, Rome, 1952, Vol. 2, p. 261. Rosenberg and Sellier, Torino.

Meinardus, K. (1958). Úber Schädelveränderungen bei Neurofibromatosis Recklinghausen. Radiol. clin. (Basel), 27, 357.

Ormea, F. and Depaoli, M. (1954). Sui rapporti tra morbo di Recklinghausen e sindrome di Ehlers-Danlos. Dermatologica (Basel), 108, 165.

Ortiz de Zarate, J. C. (1954). Sur la neurofibromatose centrale de Recklinghausen dans ses relations avec les gliomes du nerf optique. Acta neurol. psychiat. belg., 54, 716.

Payne, R. A. (1960). Metaplasia in a nerve-sheath sarcoma in von Recklinghausen's disease. Brit. J. Surg., 47, 688. 
Penrose, L. S. (1938). A Clinical and Genetic Study of 1280 Cases of Mental Defect. Spec. Rep. Ser. med. Res. Coun., No. 229. H.M.S.O., London.

Poursines, Y., Alliez, J. and Tatossian, A. (1955). Forme centrale terminale de neurogliomatose de Recklinghausen. Tumeurs parenchymateuses multiples de l'encéphale avec localisation mésocéphalique dominante. Rev. neurol., 92, 607

Preiser, S. A. and Davenport, C. B. (1918).' Multiple neurofibromatosis (von Recklinghausen's disease) and its inheritance; with description of a case. Amer. J. med. Sci., 156, 507.

Rodriguez, B., Médoc, J. and Beretervide, K. V. (1957). Contribution a l'étude des formes centrales de la maladie de Recklinghausen. Une entité particulière: la gliomatose multiple du hausen. Une entité particulière:

Russell, D. S. and Rubinstein, L. J. (1959). Von Recklinghausen's neurofibromatosis. In Pathology of Tumours of the Nervous System, p. 31. Arnold, London.

Schairer, E. (1934). Uber Neurofibromatose und ihre Beziehungen zu Gliomen und Hirnhernien. Z. Krebsforsch., 40, 30.

Scharenberg, K. and Jones, E. (1956). Diffuse glioma of the brain in von Recklinghausen's disease. A study with silver carbonate. Neurology (Minneap.), 6, 269.

Schirren, C. and Buhl, I. (1959). Dermatolysis (Alibert) bei Morbus Recklinghausen und Kleinwuchs. Hautarzt, 10, 65

Schmincke, A. (1956). Recklinghausensche Krankheit. In O Lubarsch, F. Henke and R. Rössle's Handbuch der speziellen pathologischen Anatomie und Histologie, Band 13, Nervensystem, part 4, p. 664 ed. W. Scholz. Springer, Berlin.
Shapland, C. D. and Greenfield, J. G. (1935). A case of neurofibromatosis with meningeal tumour involving the left optic nerve Trans. ophthal. Soc. U.K. 55, 257.

Sillevis Smitt, W. G. and Bijl, L. (1955). Monk cap naevus, congenital kyphoscoliosis, angiomatosis and sarcomatosis of the central nervous system all combined in one patient. (An atypical case of Recklinghausen's disease.) Folia psychiat. neerl., 58, 296

Thies, W. (1954). Beitrag zur Histogenese der Recklinghausenschen Neurofibromatose der Haut unter besonderer Berücksichtigung des vegetativen Nervensystems. Arch. Derm. Syph. (Berl.), des, 619 .

Turner, O. A. and Gardner, W. J. (1938). Familial involvement of the nervous system by multiple tumors of the sheaths and enveloping membranes. Hereditary, clinical, and pathological study of central and peripheral neurofibromatosis. Amer. J. Cancer, 32, 339 .

Willis, R. A. (1958). Neurofibromatosis and its congeners. In The Borderland of Embryology and Pathology, p. 355. Butterworth, London.

Worster-Drought, $\dot{C}$., Dickson, W. E. Carnegie and McMenemey, W. H. (1937). Multiple meningeal and perineural tumours with analogous changes in the glia and ependyma (neurofibroblastomatosis) with report of 2 cases. Brain, 60,85 .

Zacks, A. (1960). Atlanto-occipital fusion, basilar impression, and block vertebrae associated with intraspinal neurofibroma, meningocele, and von Recklinghausen's disease. Radiology, 75, 223. 